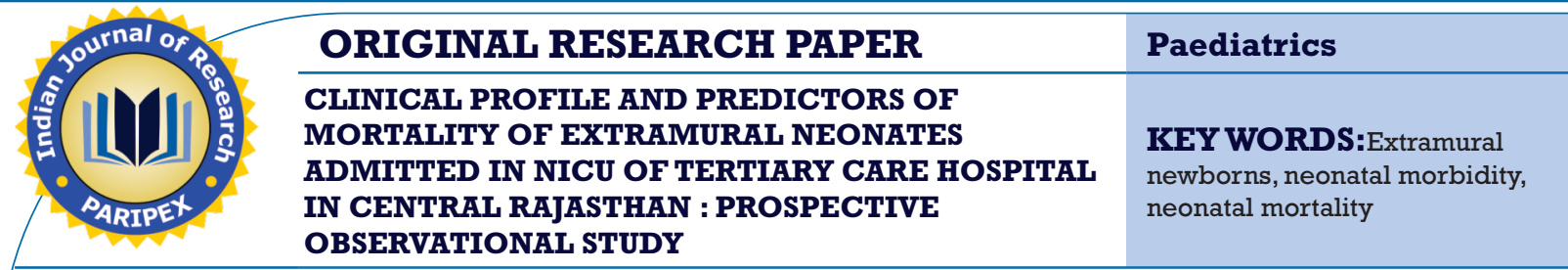

\title{
Dr. Abhilasha
}

Sharma*

\section{Dr. Pukhraj Garg}

\section{Dr. Arjun Singh}

Resident, Department Of Pediatrics, JLN Medical College, Ajmer, Rajasthan, India. *Corresponding Author

Head Of Department, Department Of Pediatrics, JLN Medical College, Ajmer, Rajasthan, India

Resident, Department OfPediatrics,JLNMedical College,Ajmer,Rajasthan,India

OBJECTIVE: This study was undertaken to know the clinical profile and predictors of mortality of outborn neonates admitted in Neonatal Intensive Care Unit (NICU).

METHOD: This prospective study was conducted in NICU of department of pediatrics, JLN medical college \& hospital, Ajmer from January 2019 to December 2019.

RESULTS: Of the 2250 neonates admitted, There was male preponderance (64\%), male:female ratio was 1.78: 1. Majority of neonates $(68.4 \%)$ were term while $31.2 \%$ were preterm and $0.4 \%$ were post term gestation. Majority of neonates (79.8\%) were admitted in early neonatal period while $20.1 \%$ neonates were admitted in late neonatal period. As per birth weight, $44.1 \%$ neonates were between $1.5-2.49 \mathrm{~kg}, 42.6 \%$ neonates had birth weight more than $2.5 \mathrm{~kg}$ while $3.4 \%$ neonates were $<1 \mathrm{~kg}$. Majority of neonates $(88.7 \%)$ were delivered vaginally while $11.3 \%$ were delivered by caesarean section. Majority of neonates (85.1\%) were delivered at govt. hospitals while $11 \%$ and $3.9 \%$ neonates were delivered at private hospitals and at home respectively. Rural residency $(73.7 \%)$ was far more as compared to urban residency (26.3\%). 42.8\% mothers had primary education and $47.7 \%$ mothers had secondary education while $3.8 \%$ mothers were illiterate. Majority of cases (66.1\%) belonged to middle socioeconomic class. Major causes of NICU admission were birth asphyxia / HIE of newborn (21.11\%), neonatal sepsis (16.36\%), neonatal jaundice (12\%), RDS of newborn (8.6\%), and prematurity (7.7\%). Out of 2250 neonates admitted, $70.1 \%$ babies were successfully discharged while $29.9 \%$ neonates died during treatment. Birth Asphyxia / HIE of Newborn (22.25\%), RDS of Newborn (20.47\%), Neonatal Sepsis (16.02\%), Shock (10.98\%), Congenital Malformations (6.82\%), and ELBW (6.38\%) were found to be major causes of mortality among neonates admitted in NICU.

CONCLUSION: The majority of morbidities and subsequently the mortalities can be reduced by improving maternal care and essential newborn care, appropriate primary interventions and timely referral to tertiary care centers for high risk cases, with better transport facilities for sick neonates.

\section{INTRODUCTION}

Childhood mortality and morbidity reflect overall development of a nation. Globally 2.5 million children died in the first month of life in 2018 , out of them approximately 1 million dying on first day and close to 1 million dying within the next 6 days. Of these about 6 lakh are Indian (UNICEF 2018) [1]. UNICEF (2014) estimate that leading causes of newborn deaths are-

- Prematurity (35\%).

- intrapartum complications like asphyxia(24\%).

- Infections (23\%).

- Other causes such as birth defects etc (18\%).

After the launch of Janani-Shishu Suraksha Karyakram (JSSK), Institutional deliveries doubled between 2005-06 to 2015-16, from $39 \%$ to $79 \%$ (NFHS-4). The rollout of Integrated Management of Newborn and Childhood Illness (IMNCI) has also leads to increased contact of newborns at their households and improved detection and referral of sick newborns to health facilities. The proportion of postnatal care increase from $37 \%$ in $2005-06$ to $65 \%$ in $2015-16$ (NFHS-4) [2]. It has been estimated that health facility based interventions can reduce neonatal mortality by as much as $25-30 \%$ [3].

In this regard it would be useful to have insight into demographic and clinical profile of outborn (extramural) neonates requiring NICU admission. Therefore the present study was carried out at tertiary care hospital in central Rajasthan.

\section{MATERIALS AND METHODS}

This prospective study was conducted in neonatal intensive care unit (NICU) of department of pediatrics, JLN medical college \& hospital,Ajmer from January 2019 to December 2019.

After taking informed consent from mothers of the neonates, their details were recorded on a specially designed pretested performa. These include residential address with distance from †www.worldwidejournals.com
NICU, age, parity, previous obstetric history, socioeconomic status (assessed by Kuppuswamy scale), education status, associated medical or obstetrical illness, antenatal care during pregnancy and the duration of gestation.

Labour and delivery details about presentation and duration of labour, peripartum complications were recorded. Details regarding newborn like birth weight, gestational age, cry status at birth, neonatal reflexes, cord condition, congenital abnormalities etc were also recorded.

Thorough physical examination was done and findings were recorded. Gestation age was assessed by new Ballard scoring system for those newborn who were admitted at birth [4]. For those who presented after 72 hours of birth it was estimated by calculation from last menstrual period. Cause of admission viz. Prematurity, low birth weight, birth asphyxia, sepsis, respiratory distress, neonatal jaundice, hypoglycemia, hypothermia, intracranial hemorrhage, congenital heart disease etc. was recorded. Any relevant investigations done during hospital stay were also recorded.

Data entry and statistical analysis was performed with the help of Microsoft Excel and SPSS version 25 (IBM SPSS Statistics inc. Chicago, Illinois, USA). Categorical variables were presented as number and percentage. Chi-square test was used to compare differences in categorical variables and independent t-test, $\mathrm{p}$ value $<0.05$ (at 95\% confidence interval) was considered to indicate statistical significance.

Prior approval for the study was taken from institutional ethical committee of JLN Medical collage Ajmer. Informed consent was taken from mothers.

\section{RESULTS}

Among 2250 neonates admitted in NICU, 64\% were males and 36 were females. HighMale:Female ratio (1.78:1) was observed. 
PARIPEX - INDIAN JOURNAL OF RESEARCH | Volume - 10 | Issue - 0 and $0.4 \%$ were post term gestation. Majority of neonates (79.8\%) were admitted in early neonatal period while $20.1 \%$ neonates were admitted in late neonatal period. As per birth weight, $44.1 \%$ neonates were between $1.5-2.49 \mathrm{~kg}, 42.6 \%$ neonates had birth weight more than $2.5 \mathrm{~kg}$ while $3.4 \%$ neonates were $<1 \mathrm{~kg}$. Majority of neonates $(87.5 \%)$ were delivered vaginally while $11.3 \%$ were delivered by caesarean section. Majority of neonates (85.1\%) were delivered at govt. hospitals while $11 \%$ and $3.9 \%$ neonates were delivered at private hospitals and at home respectively. Rural residency (73.7\%) was far more as compared to urban residency (26.3\%). $42.8 \%$ mothers had primary education and $47.7 \%$ mothers had secondary education while $3.8 \%$ mothers were illiterate. Most of the Neonates belonged middle class. Major causes of NICU admission were Birth asphyxia / HIE of Newborn (21.11\%), Neonatal sepsis (16.36\%), Neonatal Jaundice (12.0\%), RDS of newborn (8.6\%), Prematurity (7.7\%). Birth Asphyxia/HIE of Newborn (22.25\%), RDS of Newborn (20.47\%), Neonatal Sepsis (16.02\%), Shock (10.98\%), Congenital Malformations (6.82\%), and ElBWW (6.38\%) were found to be major causes of mortality among neonates admittedinNICU.

Table 1 Sociodemographic and neonatal profile of the study population

\begin{tabular}{|c|c|c|}
\hline Variables & $\begin{array}{l}\text { total admission } \\
(\mathrm{n}=2250)\end{array}$ & Percents (\%) \\
\hline \multicolumn{3}{|l|}{ Gender } \\
\hline Male & 1441 & 64 \\
\hline Female & 809 & 36 \\
\hline \multicolumn{3}{|l|}{ Gestational age } \\
\hline Fullterm (37-42 Weeks) & 1538 & 68.4 \\
\hline Preterm $(<37$ Wee s) & 704 & 31.2 \\
\hline Postterm (>42 weeks) & 08 & 0.4 \\
\hline \multicolumn{3}{|l|}{ Postnatal age } \\
\hline 0 - 3 days & 1523 & 67.7 \\
\hline $4-7$ days & 273 & 12.1 \\
\hline $8-14$ days & 214 & 9.5 \\
\hline $15-28$ days & 233 & 10.4 \\
\hline$>28$ days & 7 & 0.3 \\
\hline \multicolumn{3}{|l|}{ waight on admission } \\
\hline$<1 \mathrm{~kg}$ & 77 & 3.4 \\
\hline $1-1.49 \mathrm{~kg}$. & 223 & 9.9 \\
\hline $1.5-2.49 \mathrm{~kg}$ & 991 & 44.1 \\
\hline$\geq 2.5 \mathrm{~kg}$ & 959 & 42.6 \\
\hline \multicolumn{3}{|l|}{ Mode of delivery } \\
\hline Normal vaginal delivery & 1970 & 87.5 \\
\hline Cesarean section & 253 & 11.3 \\
\hline Assisted vaginal delivery & 27 & 1.2 \\
\hline \multicolumn{3}{|l|}{ Place of delivery } \\
\hline Hospital & 2163 & 96.1 \\
\hline Home & 87 & 3.9 \\
\hline \multicolumn{3}{|l|}{ Area of residence } \\
\hline Rural & 1659 & 73.7 \\
\hline Urban & 591 & 26.3 \\
\hline \multicolumn{3}{|c|}{\begin{tabular}{|l|l|} 
Education status of mothers \\
\end{tabular}} \\
\hline Graduates & 131 & 5.7 \\
\hline Secondary education & 1074 & 47.7 \\
\hline Primary education & 956 & 42.8 \\
\hline Illiterate & 89 & 3.8 \\
\hline \multicolumn{3}{|l|}{ Socio Economic status } \\
\hline Lower class & 621 & 27.6 \\
\hline middle class & 1585 & 70.4 \\
\hline Upper Class & 44 & 1.9 \\
\hline
\end{tabular}

Table 2 Morbidity and mortality pattern of outborn referral neonate

\begin{tabular}{|l|l|l|}
\hline Clinical Diagnosis & $\begin{array}{l}\text { Total } \\
\text { Admission } \\
(\mathrm{n}=2250)\end{array}$ & $\begin{array}{l}\text { Mortality } \\
(\mathrm{n}=674)\end{array}$ \\
\hline $\begin{array}{l}\text { Birth Asphyxia: P 21.0 / HIE of } \\
\text { Newborn: P 91.6 }\end{array}$ & 475 & $150(22.25 \%)$ \\
\hline
\end{tabular}

\begin{tabular}{|l|l|l|}
\hline RDS of Newborn (HMD): P 22.0 & 197 & $138(20.47 \%)$ \\
\hline Neonatal Sepsis: P 36.9 & 368 & $108(16.02 \%)$ \\
\hline Shock: R 57 & 76 & $74(10.98 \%)$ \\
\hline Congenital Malformation & 92 & $46(6.82 \%)$ \\
\hline E.L.B.W. (999 gm or less): P 07.0 & 46 & $45(6.38 \%)$ \\
\hline $\begin{array}{l}\text { Neonatal Aspiration of Meconium:P } \\
\text { 24.0 }\end{array}$ & 89 & $37(5.49 \%)$ \\
\hline Prematurity (28-<37 Weeks): P 07.3 & 176 & $25(3.71 \%)$ \\
\hline DIC: P 60 & 15 & $15(2.22 \%)$ \\
\hline Acquired Pneumonia: J 15 & 68 & $10(1.48 \%)$ \\
\hline Meningitis: G 00 & 26 & $8(1.19 \%)$ \\
\hline $\begin{array}{l}\text { Extreme Immaturity (<28 Weeks) : } \\
\text { P 07.2 }\end{array}$ & 7 & $7(1.04 \%)$ \\
\hline $\begin{array}{l}\text { Other Low Birth Weight(1000 gm } \\
-2499 \text { gm): P 07.1 }\end{array}$ & 70 & $4(0.59 \%)$ \\
\hline Acute Renal Failure: N 17 & 37 & $2(0.29 \%)$ \\
\hline Convulsions of Newborn: P 90 & 27 & $2(0.29 \%)$ \\
\hline IntraventricularHemorrhage:P 52.3 & 2 & $2(0.29 \%)$ \\
\hline Congenital Pneumonia: P 23 & 3 & $1(0.15 \%)$ \\
\hline $\begin{array}{l}\text { Environmental } \\
\text { Hyperthermia of Newborn: P 81.0 }\end{array}$ & 90 & $0(0.00 \%)$ \\
\hline Hemolytic Disease of Newborn:P 55 & 14 & $0(0.00 \%)$ \\
\hline Hypothermia of Newborn: P 80 & 11 & $0(0.00 \%)$ \\
\hline Neonatal Diarrhoea: A 09 & 23 & $0(0.00 \%)$ \\
\hline Neonatal Jaundice: P 59 & 273 & $0(0.00 \%)$ \\
\hline $\begin{array}{l}\text { Small for Gestational Age (IUGR):P } \\
\text { 05.1 }\end{array}$ & 10 & $0(0.00 \%)$ \\
\hline $\begin{array}{l}\text { Transient Tachypnoea of } \\
\text { Newborn: P 22.1 }\end{array}$ & 55 & $0(0.00 \%)$ \\
\hline
\end{tabular}

\section{Table 3}

Association of Gestational Age with Outcome (n=2250) Gestational Age Outcome (Indicator of Mortality)

\begin{tabular}{|c|c|c|c|}
\multirow{2}{*}{ Gestational Age } & Outcome (Indicator of Mortality) & \\
\cline { 2 - 4 } & DISCHARGED & EXPIRED (n=674) & Total \\
\hline FULLTERM (37- & $1184(76.99 \%)$ & $354(23.01 \%)$ & 1538 \\
<42 Weeks) & & & \\
\hline $\begin{array}{c}\text { PRETERM (<37 } \\
\text { Weeks) } \\
\text { POSTTERIM } \\
\text { (=>42 Weeks) }\end{array}$ & $388(55.12 \%)$ & $316(44.88 \%)$ & 704 \\
\cline { 2 - 4 } Total & 4 & & \\
\hline
\end{tabular}

Out of 704 Preterm neonates, 316 (44.88\%) neonates expired as compared to 1538 Term neonates, out of which 354 $(23.01 \%)$ neonates expired.

Table 4

\begin{tabular}{|c|c|c|c|c|}
\hline \multicolumn{5}{|c|}{$\begin{array}{l}\text { Association of postnatal age at admission with Outcome } \\
\qquad(\mathrm{n}=2250)\end{array}$} \\
\hline \multirow{2}{*}{$\begin{array}{c}\text { Age } \\
\text { (days) }\end{array}$} & \multicolumn{2}{|c|}{ Outcome (Indicator of mortality) } & \multirow[t]{2}{*}{ Total } & \multirow{2}{*}{\begin{tabular}{|c|c}
$\mathbf{P}$ \\
value
\end{tabular}} \\
\hline & DISCHARGED & EXPIRED $(\mathrm{n}=674)$ & & \\
\hline $0-3$ & 995 & 528 & 1523 & $<0.001$ \\
\hline 4-7 & 226 & 47 & 273 & $<0.001$ \\
\hline $8-14$ & 155 & 59 & 214 & \\
\hline$>15$ & 200 & 40 & 240 & \\
\hline Total & 1,576 & 674 & 2,250 & \\
\hline
\end{tabular}

Majority of neonatal mortality belonged to early neonatal age group, as the results are statistically significant ( $p$ value $<0.001$ )

Table 5

\begin{tabular}{|c|c|c|c|}
\hline \multicolumn{4}{|c|}{ Association of Birth wt. of neonates with outcome (n 2250) } \\
\hline \begin{tabular}{|c|} 
Birth \\
weight
\end{tabular} & \multicolumn{2}{|c|}{ Outcome (Indicator of mortality) } & \multirow{2}{*}{ Total } \\
\hline \multirow{4}{*}{$\begin{array}{c}\text { < } 1 \mathrm{~kg} . \\
1-1.49 \\
\mathrm{~kg} .\end{array}$} & DISCHARGED & EXPIRED & \\
\hline & & & \multirow[t]{2}{*}{77} \\
\hline & 5 & 72 & \\
\hline & 111 & 112 & 223 \\
\hline \multirow{3}{*}{$\begin{array}{c}1.5-2.49 \\
\mathrm{~kg} . \\
\geq 2.5 \mathrm{~kg} . \\
\text { Total }\end{array}$} & 706 & 285 & 991 \\
\hline & 754 & 205 & 959 \\
\hline & 1576 & 674 & 2250 \\
\hline
\end{tabular}


Majority of neonatal mortality belonged to low birth weight neonates

\section{DISCUSSION}

There was total of 2250 babies admitted in NICU during period of 12 months. The demographic distribution of population in this study finds that $1441(64 \%)$ male and 809 $(36 \%)$ female neonates were admitted which is in concordance to National Neonatal-Perinatal Database (NNPD) and other studies of rural India ${ }^{[5,6]}$. This study shows a high male : female ratio (1.78:1). Further studies are needed to determine whether this is due to gender bias prevalent in India where male children are given more care or greater tendency of male children to face neonatal complications.

In this study about two third of the neonates were of full term $(68.4 \%)$ gestation and about one third were preterm $(31.2 \%)$ which is similar to another study conducted by Gauchan et $\mathrm{al}^{\left[{ }^{[]]}\right.}$ in which there were $67.5 \%$ term babies and $31.3 \%$ preterm babies. In contrast to this finding, A study conducted by Seyal et al found that $42.8 \%$ neonates were preterm. ${ }^{[8]}$ Finding in this study is understandable because probably Janani SurakshaYojana (JSY) and Janani Shishu Suraksha Karyakram (JSSK) Scheme of National Rural Health Mission (NRHM) has enhanced the ante-natal check up, hospital deliveries and neonatal care among the general population.

This study finds that $67.7 \%$ neonates were admitted within 3 days of birth, $12.1 \%$ neonates were age group of 4-7 days, $9.5 \%$ neonates were age group of $8-14$ days, $10.4 \%$ neonates were age group of 15-28 days. Similar findings are found in study by Anjum et al (2009) ${ }^{[9]}$ and by KotwalYS (2017) ${ }^{[10]}$ These findings are expected as neonates in early neonatal period are at risk of contracting diseases and at risk neonates are identified by healthcare workers immediately if they are born in hospitals.

The weight parameter analysis revealed that the number of neonates having extremely low birth weight $(<1000 \mathrm{gm})$ were $3.4 \%$, very low birth weight $(1000-1499 \mathrm{gm})$ were $9.9 \%$, low birth weight (1500-2499 gm) were $44.1 \%$, normal weight (>2500 gm) were $42.6 \%$. According to the United Nations International Children's Education fund (UNICEF), The state of world's children's report $28 \%$ of neonates born with low birth weight in India. ${ }^{[1]}$ But in our study total $57.4 \%$ of neonates were low birth weight, this pattern of admission in NICU is in concordance with National Neonatal Perinatal Database (NNPD). ${ }^{[2]}$ The results of this study are also comparable with similar study done by Rakholia R et al (2014) which revealed that extremely low birth weight were $3.19 \%$, very low birth weight were $15.40 \%$, low birth weight were $42.02 \%$ and normal weight were $39.39 \% .^{\left[{ }^{[3]}\right.}$

This study revealed that most of the admitted neonates were delivered in health institutions $(96.1 \%)$ out of which $85.1 \%$ at govt. hospitals and $11 \%$ delivered at private nursing homes. Only small number of babies were born at home $3.9 \%$. Similarly Kotwal YS et al (2017) finds in their study at Govt. medical college Srinagar, Jammu and Kashmir that $90 \%$ babies were delivered at health institutions and $10 \%$ were delivered at home. ${ }^{[10]}$ The finding of more number of health institutional deliveries are probably due to Janani Suraksha Yojana and Janani Shishu Suraksha Karyakarm scheme of National Rural Health Mission.

It was observed that $73.7 \%$ patients admitted were from rural areas and $26.3 \%$ were from urban areas. This finding is understandable as the rural population outnumbers the urban population in the catchment area of the NICU of JLN medical college Ajmer. These findings are corroborating with the study of Salve et al who reported the morbidity pattern of neonates admitted at tertiary care hospital, Dr. S.C. Government Medical Collage, Nanded, Maharashtra and observed that the $76 \%$ neonates were from rural areas and only $24 \%$ from urban areas. ${ }^{[14]}$
In this study literacy rate of mothers is $96.2 \%$, out of which $42.8 \%$ have primary education, $47.7 \%$ have secondary education and $5.7 \%$ were graduated.In the present study, most cases (92\%) belonged to the socioeconomic class Upper middle, Lower middle and lower. This may be due to the fact that representation of most of the population belongs to these classes. Purohit et al (2014) finds in his study that health and survival of the newborn babies depends upon the education, socioeconomic status and health status of mothers. ${ }^{[15]}$

Top five causes of admission of neonates in this study are Birth asphyxia / HIE of Newborn (21.11\%), Neonatal sepsis (16.36\%), Neonatal Jaundice (12.0\%), RDS of newborn (8.6\%), Prematurity (7.7\%).The other cause of admission are Congenital malformations (4.1\%), Environmental hyperthermia of newborn (4.0\%), Shock (4\%), neonatal aspiration of meconium (3.9\%), Low birth weight (3.2\%), Acquired pneumonia (3.0\%), Transient tachypnoea of newborn (2.1\%), Extremely low birth weight (2.1\%), Acute renal failure (1.6\%), Convulsions of newborn (1.2\%), and others $(4.07 \%)$.

The type of diseases in this study is similar to other studies conducted by prakash et $\mathrm{al}^{\left[{ }^{[16]}\right.}$ Islam et $\mathrm{al},{ }^{[17]}$ Anjum et al,${ }^{[9]}$ Elhassan et al,${ }^{[18]}$ Hoque et al,${ }^{[19]}$ Gauchan et al, ${ }^{[7]}$ Prasad et al, ${ }^{\left[{ }^{[20]}\right.}$ Seyal et al, ${ }^{\left[{ }^{[1]}\right.}$ Narayan et al, ${ }^{[2]}$ Aijaz et al, ${ }^{[22]}$ and Kotwal et

However, the pattern of disease in this study was not similar to the above mentioned studies, which is probably due to different racial stock, socioeconomic status, education status, health care facilities and climatic conditions at Ajmer region. The major causes of morbidity were birth asphyxia (30\%), neonatal sepsis (30\%) and prematurity along with jaundice, pneumonia, meningitis, congenital heart disease, diarrhoea and haemorrhage disease of newborn in Anjum ZM and Shamoon. ${ }^{\left[{ }^{[1]}\right.}$ The commonest indications for admission were neonatal jaundice $(24.7 \%)$, sepsis $(21.4 \%)$, and perinatal asphyxia $(19.2 \%)$ in Gauchan et al study. ${ }^{[7]}$ In Seyal et $a{ }^{[8]}$ study the main cause of admission was prematurity (23.5\%), sepsis $(21.9 \%)$, birth asphyxia (18\%) and neonatal jaundice (11.3\%) respectively. The most common disease was sepsis $(19.9 \%)$, followed by respiratory distress syndrome (18.9\%), birth asphyxia (17.02\%), meconium aspiration syndrome $(15.2 \%)$, neonatal jaundice $(9.44 \%)$, pneumonias $(3.46 \%)$ in Aijaz et $a{ }^{[22]}$ In Kotwal et $a{ }^{[10]}$ study the main cause of admission was neonatal jaundice (26.7\%), septicaemia $(19.1 \%)$, prematurity (12.5\%), birth asphyxia (7\%) Respiratory Distress Syndrome (5.7\%). In this study it was observed that out of 2250 neonates admitted, $1576(70.1 \%)$ of the neonates were discharged and 674 (29.9\%) expired.

The mortality rate observed in this study was $29.9 \%$ which is similar to study conducted by Prakash et al (25.5\%), ${ }^{[16]}$ Tallatseyal et al (30.9\%) ${ }^{[23]}$, Malik S et al (26.6\%) 2016, ${ }^{[24]}$ Soni LK et al $(20.19 \%)^{[25]}$, Preeti Anil Bhai Shah et al $(29.5 \%)^{[26]}$. Much lower mortality rates were observed in study by Kotwal YS et al $(9.73 \%),{ }^{[10]}$ Sarkar et al $(7.5 \%),{ }^{\left[{ }^{27]}\right.}$ Ravi Kumar SA $(10.45 \%),{ }^{\left[{ }^{[28]}\right.}$ and Sridhar PV et al $(7.16 \%) .{ }^{[29]}$. In above studies both inborn and outborn neonates were included in observations and higher mortality was observed in outborn neonates as compared to inborn neonates. Higher mortality in this study is understandable as only outborn neonates are admitted at NICU of JLN medical college Ajmer which are referred from other health centers mainly in serious conditions.

Disease specific mortality revealed that three common causes of death are birth asphyxia/HIE of Newborn (22.25\%), RDS of Newborn $(20.47 \%)$ and Neonatal sepsis (16.02\%) which is similar to different studies Baruah MN et al ${ }^{[30]}$ Ranjan et $\mathrm{al}^{[31]}$, Kumar $\mathrm{R}$ et $\mathrm{al}^{[32]}$ though incidence of these three causes vary among studies.

\section{CONCLUSION}

Present study revealed that birth asphyxia, RDS of newborn, 
neonatal jaundice, prematurity were common causes of morbidities in newborn babies. RDS of newborn, neonatal sepsis, birth asphyxia and congenital malformations were leading causes of neonatal mortality.

The majority of morbidities and subsequently the mortalities can be reduced by improving maternal care and essential newborn care, appropriate primary interventions and timely referral to tertiary care centers for high risk cases, with better transport facilities for sick neonates.

\section{ACKNOWLEDGEMENTS: Nil}

\section{DECLARATIONS}

Funding: Nil conflict of interest: Nil ethical approval: This study was approved by institutional ethical committee

\section{REFERENCES}

1. UN - Interagency Group For Child Mortality Estimation (UN-IGME 2019) http://data.unicef.org>childsurvival

2. BR_fact sheet.pdf. Available from http:// rchiips org NFHS/ pdf/ NFHS4/BR factsheet. pdf

3. Lawn JE, Cousens S,Zupan J. Lancet Neonatal Survival Streening Team; 4 million neonatal deaths; When?Where?Why? Lancet. 2005;365;891-900.

4. Ballard JL, Khoury JC, Wedig K, et al: New Ballard Score expanded to include extremely premature infants.JPediatr, 1991:119 (3):417-423.

5. Morbidity and mortality among outborn neonates at 10 tertiary care institutions in india during the year 2000. JTrop Pediatr 2004; 50:170-4.

6. Bhatia BD, Mathur NB, Chaturvedi P, Dubey AP. Neonatal mortality pattern in rural based Medical college hospital. Indian J Pediatr 1984;51:309-12.

7. Gauchan E, Basnet S, Koirala DP, Rao KS (2011). Clinical profile and outcomes of babies admitted to Neonatal Intensive Care Unit 33:1-8. 10.Seyal T, Husnain F, Anwar A (2011). Audit of Neonatal Morbidity and Mortality at Neonatal Unit of Sir Gangaram Hospital Lahore. Annals King Edward Med Coll 1:9-13.

8. Seyal T, Husnain F, Anwar A (2011). Audit of Neonatal Morbidity and Mortality at Neonatal Unit of Sir Gangaram Hospital Lahore.Annals King Edward Med Coll 1:9-13.

9. Anjum ZM, Shamoon M(2009) Pattern of Neonatal unit of Allied hospital Faisalabad Pakistan. Annals Punjab Med Col 3:129-131.

10. Kotwal YS, Yatoo GH, Ahmed Jan FA (2017) Morbidity and Mortality among Neonates admitted to a tertiary care teaching hospital of jammu and Kashmir(india). Neonatpediatr Med 3:136.

11. UNICEF. The state of the world's children 2010. New York: UNICEF 2010:925.Available at https://www.unicef.org/rightsite /sowc/pdfs/ SOWC Spec\%20Ed CRC Main\%20Report EN 090409.pdf.

12. http://www.newbornwhocc.org/pdf/nnpd_report_20022003.PDF

13. Rakholia R., Vineeta R., Bano M., and Singh G.(2014). Neonatal morbidity and mortality of sick newborns admitted in a teaching hospital of Uttarakhand. CHRISMED J Health Res 2014;1:228-34.

14. Salve D, Inamdar IF, Sudhir S, Mohan D, Saleem T, Sahu P. Study of profile and outcome of the Newborns admitted in Neonatal Intensive care Unit at tertiary care Hospital in a city of Maharastra. Int J Health Sci Res. 2015;5(10):18-23.

15. Purohit U et al, Study on knowledge, attitude and practice of rural and urban population in care of newborn. 2014, RUHS, Rajsthan.

16. Prakash J, Das N(2005). Pattern of admission to neonatal unit.J Coll Physician Surg Pak 15:341-344.

17. Islam $\mathrm{MN}(2000)$. Situation of neonatal health in Bangladesh. The Orion Medical Journal 6:3-6.

18. Elhassan EM, Hassanb AA, Mirghani OA, Adam I(2010). Morbidity and Mortality Pattern of Neonates Admitted into Nursery Unit in Wad Medani Hospital, Sudan. Sudan JMS 5:13-15.18*

19. Hoque M, Haaq S, Islam R (2011).causes of neonatal admissions and deaths at a rural hospital in KwaZulu-Natal, South Africa. South Afri J Epidemiol Infect 26:26-29.

20. Prasad V, Singh N(2011). Causes of morbidity and mortality in neonates admitted in government medical college Haldwaniin Kumaon Region (Uttrakhand) india. Journal of Pharmaceutical and Biomedical Sciences 8:1-4.

21. Narayan R(2012). A study of pattern of admission and outcome in a neonatal intensive care unit at high altitude. Sri Lanka Journal of Child Health 41:79-81.

22. Aijaj N, Huda N, KausarS(2012). Disease Burdan of NICU at a Tertiary Care Hospital, Karachi.J Dow Univ health Sci. Karachi 6:32-35.

23. Tallatseyal, Fozia Husnain, Asmaanwar Audit of neonatal morbidity and mortality at neonatal unit of Sir Gangaram hospital Lahore annals vol 17,no. 1Jan-march 2011.

24. Malik S, Gohiya P, Khan IA. Morbidity profile and mortality of neonates admitted in Neonatal Intensive Care Unit of a Central India Teaching Institute: A prospective observational study.J Clin Neonatol.2016;5:168-

25. Soni LK, Rathore P and Rani N. 2019, Neonatal Morbidity and Mortality Profile of Newborns Admitted in sncu @ It. Lam Government Medical College, Raigarh, Chhattisgarh. Int JRecent Sci Res. 10(01), pp.3058130585.

26. Preeti Anil Bhai Shah et al, A study of correlation of TOPS score with outcome of Referred Neonates.NJCM| volume 11 | issue 5 | May 2020.

27. Sarkar S, Sarkar D, Longia S, SibiD(2010). NICU Outcome in a Low resource Teaching Hospital Setting. Pediatric Oncall.

28. Ravi kumar SA, Elangovan H, Elayaraja K, Sunderavel AKK. Morbidity and mortality profile of neonates in a tertiary care centre in Tamilnadu: a study from south India. Int J Contemp Pediatr 2018;5:377-82.

29. Sridhar PV, Thammanna PS, Sandeep M. Morbidity pattern and hospital outcome of Neonates Admitted in a Tertiary Care Teaching Hospital, Mandya.Int J Sci Stud 2015;3(6):126-129.

30. Baruah MN, Panyang PP. Morbidity and mortality Profile of Newborns Admitted to the Special CareNewborn Unit (SCNU) of a Teaching Hospital of UpperAssam, India- A Three Year Study. Journal of MedicalScience and Clinical Research. 2016;4(8): 11689-95.
31. Ranjan A, Singh A. Pattern of morbidity and mortality of neonates admitted in tertiary level neonatal intensive care unit in Nalanda Medical College and Hospital, Bihar, India. International Journal of Contemporary Pediatrics. 2016; 13:854-7.

32. Kumar R,Mundhra R, Jain A, Jain S. Morbidity and mortality profile of neonates admitted in special newborn care unit of a Teaching Hospital inUttarakhand India. International Journal of Research in Medical Sciences. 2019;17(1):2416. 